\author{
MARIA JOSÉ GOULÃO \\ UNIVERSIDADE DE PORTO
}

\title{
A arte da prataria no Brasil e no Rio da Prata no período colonial: estudo comparativo *
}

A REGIÃO D O RIO DA Prata, integrada nos territórios da Coroa espanhola, e o Brasil, colónia portuguesa, mantiveram, durante todo 0 período colonial, relações muito estreitas a vários níveis. Esta situação leva a que, em muitas ocasiões, Buenos Aires e a sua região mais pareçam um prolongamento natural da colónia portuguesa do que uma zona rival. As semelhanças entre ambas as regiões revelam-se não apenas no plano geográfico ou ao nível das formas de organização social e económica, mas também no domínio cultural e artístico, de tal modo que, ao longo de vários séculos, encontramos nos fenómenos de gosto e nas manifestações artísticas da região platina uma muito maior aproximação dos modelos lusobrasileiros do que dos modelos importados directamente de Espanha, ou comuns a toda a zona do Vice-Reino do Perú, onde o Rio da Prata se integrava política e institucionalmente. A aceitação dos modelos artísticos lusobrasileiros, que suplantam largamente a influência peruana ou espanhola, tem que ver com toda uma situação de interdependência, que procuraremos explicar e caracterizar em breves palavras.

* A autora gostaria de expressar o seu agradecimento à Comissão N acional para as Comemorações dos $D$ escobrimentos Portugueses, que viabilizou a sua deslocação a este $C$ ongresso, tendo igualmente patrocinado muito do trabalho de pesquisa realizado em território sul-americano. De igual modo, gostaria de salientar e agradecer todo o apoio prestado pelas instituições, coleccionadores, amigos e colegas brasileiros, argentinos e uruguaios. Esta comunicação, com algumas modificações, foi posteriormente apresentada no Brasil, no IV Colóquio Luso-Brasileiro de H istória da Arte, realizado em S. Salvador, Bahia, em Setembro de 1997. 
A economia e a sociedade do Rio da Prata desenvolveram-se à volta de dois grandes centros de actividade colonial: o complexo mineiro de Potosí e, mais tarde, o porto comercial de Buenos Aires. Esta cidade fornecia artigos de luxo estrangeiros e escravos negros a Potosí, servindo também como um importante centro ilegal para a exportação da prata peruana. O bviamente, como área dependente de Potosí, e fornecedora daquela cidade, a zona do Rio da Prata mantinha um desenvolvimento económico e social correspondente ao daquela região. ${ }^{\text {I }}$

D esde a segunda e definitiva fundação da cidade de Buenos Aires, em I580, data, igualmente, da união das duas coroas ibéricas, que esta modesta cidade costeira, situada numa zona inóspita e desprovida de riquezas naturais, viveu uma situação de subalternidade. Afastada da capital do ViceReino do Perú, onde se inseria, e dependente, para fins judiciais, da Audiência de C harcas, nada parecia predestiná-la a um futuro brilhante. A implantação de um povoado nessa zona do estuário do Prata estivera essencialmente dependente de considerações estratégicas, e a cidade era mais uma peça na defesa da zona meridional dos territórios de C astela, e na luta pela soberania naquela região. D epressa a região foi esquecida pela governação espanhola, mais ocupada com os territórios a norte, onde se situava a fonte máxima da riqueza, os centros mineiros considerados pelo vice-rei Toledo como os eixos onde andam as rodas de todo este Reino, e a fazenda que vossa $M$ agestade tem. ${ }^{2}$

No entanto, rapidamente os habitantes da cidade, e sobretudo os portugueses da zona fronteiriça, que logo desde o início passam para o Rio da Prata, percebem o interesse económico da região, como ligação única e privilegiada, pela via atlântica, ao interior do vicereino do Perú, e sobretudo ao altiplano andino e às minas de prata.

Potosí, O ruro e la Paz eram abastecidas por Buenos Aires, em detrimento de Lima e do porto de $C$ allao, destinos oficiais dos navios fretados pela C asa da Contratação de Sevilha. A maior parte dos três milhões de pesos produzidos anualmente em Potosí passavam a Buenos Aires, e raras vezes se con-

I. Jonathan C. Brown, A socioeconomic history of Argentina, 1776-I860, Cambridge, Cambridge U niversity Press, 1979, pp. 9-10.

2. Citado por C ristina Esteras M artín, "A proximaciones a la platería virreinal hispanoamericana”, em Ramón G utiérrez (coord.), Pintura, escultura y artes útiles en Iberoamérica, I5ooI825, M adrid, Cátedra, I995, p. 38I. 
seguia encontrar em Lima um peso potosino. Juntamente com a produção de $O$ ruro e la Paz, Chile, Tucumán e Paraguai, um total de mais de 4 milhões de pesos descia com destino a Buenos Aires. D esta quantia, só trezentos mil pesos viajavam para Espanha nos navios de registo. 0 restante era levado pelos portugueses. ${ }^{3}$

A fabricação da prata podia ser interrompida no estado da "pinha", quando o metal branco se apresentava sob a forma de um pequeno pão de açúcar. Com duas pinhas, obtinha-se um lingote. D evido à escassez crónica de meios de pagamento no Perú, muitas vezes a pinha circulava, escapando à pesagem, titulação e marcação, e ao arrecadamento de cerca de $20 \%$ da produção (o "quinto"). A prata não quintada podia ainda apresentar-se transformada em "prata lavrada" isto é, em objectos litúrgicos, joalharia, baixela lisa e simples de prataria colonial, usada na vida quotidiana. Pinhas e lingotes, quintados ou não, serviram de meio de pagamento. A prata não quintada tinha as suas cotações e o seu mercado negro, e saldava as aquisições ilegais com o Brasil, que escapavam ao controle da C asa da Contratação de Sevilha. ${ }^{4}$ $N$ ão é, pois, de admirar a referência constante em testamentos brasileiros dos séculos XVII e XVIII a enormes quantidades deste metal, lavradas e por lavrar.

Um bom exemplo da actividade dos contrabandistas luso-brasileiros é o caso do bispo Francisco de Vitória, um comerciante português, ingressado tardiamente na ordem dos dominicanos, em Lima. Em I577, na altura de união das duas coroas, obtém de Filipe II o bispado do Tucumán. Chegado à região em I58I, rapidamente se confessa decepcionado com a pobreza da sua jurisdição, mas quando vai ao terceiro Concílio de Lima, em I583, detém-se na região das minas de prata, e apercebe-se da sua riqueza, e da excelente posição estratégica do Tucumán, a meio caminho entre o Alto-Perú e 0 Atlântico. O btém da Audiência de Charcas licença para comerciar com 0 Brasil, parte de Buenos Aires, chega a São Vicente, onde fica 26 dias, e daí ruma à Bahía. Na volta, seis meses mais tarde, pára no Espírito Santo, no Rio de Janeiro, em São Vicente. Em 1587, o bispo Frei Francisco de Vitória envia para o Brasil, através dos seus representantes, IoIs marcos de prata tra-

3. Ricardo Levene, Investigaciones acerca de la historia económica de virreinato del Plata, La Plata, 1928 (cit. por Enrique M. Barba, Sobre el contrabando de la Colonia del Sacramento. Siglo XVIII), "I nvestigaciones y Ensayos", Buenos Aires, n-28, Janeiro-Junho i980, p. 6I.

4. Cf. M arie H elmer, Comércio e contrabando entre a Bahía e Potoś no séc. XVI, "Revista de H istória", São Paulo, Ano IV , no I5, Julho- Setembro 1953, pp. 205- 206. 
balhada que escaparam ao quinto real, 215 marcos de prata branca em lingotes subtraídos à marcação, e ouro. Em I588, um dos seus barcos, carregado com 45 mil pesos de prata, perde a sua carga na viagem para o Brasil. N 0 mesmo ano, os seus detractores denunciam ao rei a expedição de 30000 pesos de prata não quintada. 5

0 mercador Diogo Lopes de Lisboa foi igualmente um dos elos importantes nas transacções do Prata com o Brasil. Em I59I, passa daí para Buenos Aires, e de lá para o Tucumán, grangeando fortuna no comércio. Casou em Lima, 0 que lhe deve ter aberto grandes possibilidades. A seguir, muda-se para Santiago del Estero, província do Tucumán, a meio caminho entre Potosí e Buenos Aires. Estendia as suas actividades a Santafé e Córdoba. Enviúva, regressa a Portugal, e casa com uma senhora membro de uma família de judeus de É vora. Com as condenações à fogueira de vários membros da sua família, D iogo Lopes foge novamente para Buenos Aires, fixando aí residência com a sua mulher e voltando aos negócios. Em i6i4, ele e Diogo da Veiga tratan e contratan en el dicho puerto con naciones y navios de la costa del Brasil e Portugal, e parece que também da Flandres. $M$ ais tarde, ingressa na vida eclesiástica, servindo-se das boas relações com 0 arcebispo, de quem era confessor privado, para proteger os restantes portugueses, espalhados agora por todo o vicereino do Perú. ${ }^{6}$

A visitação do inquisidor $\mathrm{H}$ eitor Furtado de $\mathrm{M}$ endonça às capitanias brasileiras do centro-leste, em I591, beneficia as capitanias do sul, não sujeitas às perseguições aos judaizantes, e sobretudo o porto do Rio de Janeiro, cuja importância cresce, avolumando-se as trocas com o Rio da Prata. M ercadores de ambas as regiões estabelecem-se nos dois portos, aumentando as trocas nos dois sentidos. ${ }^{7}$

Em I594, é publicado o acto que fecha o porto de Buenos Aires ao comércio luso-brasileiro. A coroa espanhola, através do seu governo central, procura cercear o comércio ilegal, objecto de inúmeras queixas dos grandes comerciantes de Lima e de Sevilha, que vêm o seu monopólio ameaçado. D aí para a frente, só podiam atracar em Buenos Aires os barcos provenientes de Sevilha e enviados pela $C$ asa da Contratação. $M$ as a situação de intenso contra-

5. Cf. Idem, ob. cit, pp. 196-199 e 209.

6. José G onçalves Salvador, Os cristãos-novos e o comércio no Atlântico meridional (com enfoque nas capitanias do Sul I530-I680), São Paulo, Livraria Pioneira Editora, 1978, p. 68.

7. Idem, ob. cit., pp. 66-67. 
bando e imigração clandestina mantêm-se, de tal modo que, já no século XVII, num documento apresentado por uma junta ao rei, propondo a criação de um tribunal da Inquisição no Rio da Prata, se denuncia la entrada de los de la nación hebrea en las provincias del Peru por la via de Buenos Ayres, já que conviene i es muy necesario assi para la pureça de la religion catholica, como para la conservazion temporal de las provincias del Peru y las circunvezinas ataiar quanto fuere posible la emtrada y comunicacion que los christianos nuebos de la nacion hebrea de los reynos de Portugal hazen por bia de Buenos Ayres y por todo el Río de la Plata[... ] no solo por la mucha plata que sacan y mercaderias prohibidas que meten por aquellas partes. ${ }^{8}$

Em I613, haviam partido de Buenos Aires vários navios com destino ao Brasil, e dizia-se publicamente na cidade que voltariam com escravos. Em I6I4, entraram no porto de Buenos Aires is ou i6 navios de arribada, procedentes de Angola e do Brasil. Em i6i5, i3 ou i4 navios entraram da mesma maneira. ${ }^{9}$

Segundo José G onçalves Salvador, as rotas mais utilizadas, com os seus centros nas capitanias brasileiras, no Rio da Prata e em Angola, conjugavam os portos dos respectivos litorais entre si, fortaleciam a unidade geopolítica, que Ihes era comum, e, ao mesmo tempo, contribuíam para fomentar o intercurso de pessoas, de ideias e de produtos de cada região. A própria cidade de Buenos Aires encaixava-se melhor na área portuguesa do que na castelhana, pelo menos economicamente, e sobretudo enquanto durou a união das duas $C$ oroas. ${ }^{\text {Io }}$

D epois da separação das coroas portuguesa e espanhola, em I640, as relações estreitas de interdependência a nível económico mantêm-se, mesmo se contrariavam abertamente o clima de conflito armado entre ambas as potências, nesta zona fronteiriça.

No início do século XVII, os traficantes estabelecem ligações a Luanda: muitas mercadorias que chegavam ao território angolano eram desviadas para a América espanhola, juntamente com os escravos, necessários para 0

8. Archivo General de Indias, Sevilla - Indiferencia General - Reales D ecretos - Años I6I8 a I624 - Est. I40- Caj. 3 Leg. io (transcrito em José T orre Revello, N uevos datos para el estudio de la Inquisición en el Río de la Plata (con apéndice documental), Buenos Aires, Casa Editora Coni, 1930, pp. 22-23).

9. Idem, "Un contrabandista del siglo xvII en el Río de la Plata", Revista de Historia de América, Instituto Panamericano de G eografía e H istoria, M éxico, no 45, junio i958, p. I24.

Io. José Gonçalves Salvador, Os crisãosnovos e o comércio no Atlântico meridional (com enfoque nas capitanias do Sul 1530-1680), São Paulo, Livraria Pioneira Editora, 1978, p. 337. 
trabalho nas minas do Perú. 0 governador interino de Angola, capitão $M$ anuel Cerveira Pereira, manda para Buenos Aires, em menos de três anos, seis navios com mercadorias e escravos, sem licença. 0 seu sucessor, nomeado por $M$ adrid, o fidalgo $M$ anuel Pereira Forjaz, une-se a um mercador judeu, e explora uma rede de negócios que envolve a Península, as C anárias, Angola, as I ndias de C astela, a Bahía e Pernambuco. 0 traficante Paulo Roiz recebe escravos e outras mercadorias de Angola, negoceia com Córdoba, tem intermediários em Buenos Aires, em Tucumán e no Alto Perú. O s seus negócios estendem-se desde o Perú a Buenos Aires, Brasil, Península Ibérica e Países Baixos. ${ }^{\text {II }}$

A C olónia do Sacramento, fundada em i68o pelos portugueses, na outra banda, face a Buenos Aires, cedo se torna uma rival comercial desta cidade. 0 estuário atravessava-se de barco em apenas seis horas de navegação, e essa ténue distância separava o território português do da coroa espanhola. A Colónia também estava numa posição privilegiada para servir a navegação estrangeira no estuário, bem como a navegação fluvial ao longo da bacia do rio Paraná. 0 porto português atraía aos recursos pecuários da pampa uruguaia, e as caravanas de prata que vinham de Córdoba para Buenos Aires. Pequenos barcos passavam facilmente de um porto para o outro com bens de contrabando. Q uando a Companhia dos M ares do Sul (South Sea Company) perdeu a sanção oficial em Buenos Aires, os navios ingleses passaram simplesmente a atracar na Colónia, para carregarem prata e couros. Um ataque militar espanhol à Colónia do Sacramento, em i762, surpreendeu aí 27 navios mercantes ingleses. ${ }^{12}$

Em 1707, entre os habitantes de Buenos Aires encontravam-se muchas personas muy beneméritas aś por su calidad y sangre como por sus servicios, nietos y biznietos de portugueses que vinieron a poblar en tiempo de los señores reyes don Felipe II, don Felipe III y don Felipe IV, reyes que fueron legítimos de Portugal en tiempo en que esta corona estaba unida a la de Castilla, y aunque después se levantó este reino, si empre quedaron los referidos y sus ascendientes debajo del vasallaje de los dichos reyes cada uno en su tiempo con las mayores demonstraciones de amor y lealtad habiendo tomado las armas contra la corona de Portugal en todas las ocasiones que se han ofrecido del real servicio

II. Idem, ob. cit., pp. 367-368 e 369 .

I2. Jonathan C. Brown, ob. cit., p. 26. 
y especialmente en los desalojos que se han ofrecido de los portugueses que habitaban la nueva Colonia. ${ }^{13}$

Em 9 de Julho de 1753 , numa carta ao ministro espanhol Dom José de Carvajal y Lancaster, fazem-se várias acusações contra os portugueses: Son tantos, tan crecidos, tan interesados, tan desvergonzados y tan sin temor al Rey, las introducciones continuas de la Colonia y permitidas con disolución por estos O ficiales reales que no es posible creerlo a no etar presente.

Os comerciantes da cidade acusados de cumplicidade neste documento eram todos portugueses: Carlos de los Santos Balente, M anuel de O livera Braga, Bartolomé Jacinto de Q uiroga e Francisco Pérez de Saravia. ${ }^{\text {I4 }}$

Em I772, o forasteiro Francisco M illau, de visita a Buenos Aires, diz o seguinte: Hay establecido en Buenos Aires un gran número de Portugueses 0 descendientes de ellos, que con otros muchos forasteros de esa nación compondrá como una cuarta parte de sus moradores. Se avienen bien generalmente con ellos los demás naturales, sin el reparo que es común entre los extranjeros, o sea, porque su industria y habilidad en toda suerte de oficios los hace allí muy apre ciables, o porque la abundancia del país no da lugar a que fomente envidia su adelantamiento 0 estación..$^{15}$

Também do lado português há a consciência clara da importância vital do contrabando. Em carta do governador da Colónia do Sacramento, António Pedro de Vasconcelos, ao rei, em 20 de Abril de 1732, até agora inédita, pode ler-se o seguinte: Senhor(... ) correo o negocio da outra banda [Buenos Aires] com tal ímpetto, e felicidade que será a porssão de pratta, na remessa desta frotta, muy avultada, ademirando o consumo, que se tem dado às copi ozas partidas de fazenda vindas dessa cortte, Pernambuco, Bahia, e Ryo em dezanove navios entrados de todos os portos. E muito mais haverem voltado todos com carga, não obstante a deficuldade do transporte dos couros, pella infinita distançia onde se acha 0 gado. ${ }^{16}$

Vemos, pois, como a separação entre o Rio da Prata e o Brasil perdurava

I3. Archivo G eneral de la N ación, Acuerdos, série II, t. I, pp. 580 a 6I2 (cit. por José Torre Revello, La sociedad colonial (Páginas sobre la sociedad de Buenos Aires entre los siglos XVI y XIX), Buenos Aires, Pannedille, 1970, p. I7I).

I4. Cf. Enrique M. Barba, Sobre el contrabando de la Colonia del Sacramento (Siglo XVIII), "Investigaciones y ensayos", Buenos Aires, no 28, Janeiro-J unho i980, pp. 59-60.

I5. Francisco M illau, D escripción de la provincia del río de la Plata (I772) (ed. y estudio preliminar de Richard Konetzke), Buenos Aires, Espasa-C al pe Argentina, s/d, p. 43.

I6. Arquivo H istórico U Itramarino, Lisboa - N ova Colónia do Sacramento-Caixa 3-D oc. 4I, fl. I. 
apenas no plano político. À margem dos ordenamentos jurídicos e políticos, imperava uma realidade social e económica de compenetração firme e de indiscutível simbiose, que os historiadores de ambos os países têm frequentemente ignorado.

0 trajecto de barco entre Buenos Aires e as costas brasileiras incluía normalmente escalas em Puerto San Rodrigo, Santa Catarina, São Francisco, Cananeia, e depois, já em território brasileiro, em São Vicente, São Sebastião, Angra dos Reis, Rio de Janeiro, Cabo Frio, Bahia Grande, Espírito Santo e Bahía de Todos os Santos. Por essas regiões costeiras terá entrado grande quantidade de prata lavrada e por lavrar, como é referido no texto anónimo dos $D$ iálogos das $G$ randezas do Brasil, escrito em I6I8, onde se refere que do Rio da Prata costumam navegar muitos peruleiros em caravelas, e caravelas de pouco porte, onde trazem soma grande de patacas de quatro e de oi to reales, e assim prata lavrada e por lavrar, em pinhas e em postas, ouro em pó e em grãos, e ouro lavrado em candeias, os quais aportam com estas coisas no Rio de Janeiro, baía de Todos os Santos e Pernambuco, e comutam as tais coisas por fazendas das sortes que Ihes são necessárias, deixando toda prata e ouro que trouxeram na terra, donde tornam carregados das tais fazendas a fazer outra viagem para o rio da Prata. ${ }^{17}$

Está ainda por fazer o estudo aprofundado da forma como este comércio clandestino com Buenos Aires, via Colónia do Sacramento, terá eventualmente influenciado os territórios brasileiros no que diz respeito às artes em geral, e à ourivesaria em particular. Com efeito, os objectos de prata lavrada e alguns artigos de uso doméstico e religioso provenientes do Perú e Alto Perú que deram entrada nos portos daquela colónia portuguesa contribuíram certamente para modelar a feição de certos caracteres originais da arte barroca brasileira. Igualmente, sabemos que de Buenos Aires se encomendavam muitos objectos de prata lavrada ao Brasil. ${ }^{18}$

É sobretudo na ourivesaria, mais ligada a funções de representação social e religiosa, ao luxo, e portanto menos permeável a influências locais de

17. D iálogos das grandezas do Brasil, Rio de Janeiro, ed. Academia Brasileira, 1930, p. I44.

I8. Q uando o governo de Lisboa proíbe em 1766 o exercício do ofício de ourives nas capitanias do Rio de Janeiro, Pernambuco, Bahía e M inas Gerais, para obstar ao desvio do ouro do Brasil, 0 vicerei $C$ onde da Cunha protesta, alegando que ... de Buenos Aires encomendam-nos grande quantidade de obras de prata, o que trazia utilidade tanto aos artífices como ao comércio do réno, de cuja falta resultam prejuízos muito senśveis. (C it. por Fernando M arques dos Santos, "A ourivesaria no Brasil antigo", Estudos Brasileiros, ano II, vol. IV, № I2, M aio-Junho de I940, pp. 627-628.) 
índole popular, ${ }^{19}$ que a marca de um barroco e rococó eruditos, de origem luso-brasileira, é mais notável.

No início do século XVII, há notícia da chegada dos primeiros ourives lusitanos a Buenos Aires, alguns vindos de Portugal continental, outros do Brasil. A análise dos censos, padrões e estatísticas posteriores revela que 0 seu número foi extremamente significativo, e mesmo possivelmente bastante superior ao registado, já que muitos artífices luso-brasileiros preferiam ocultar a sua origem, claramente indiciada nos apelidos. Em Buenos Aires, os ourives portugueses chegaram a ser superiores, em número, aos de origem espanhola: em I788, num total de 46 ourives registados, 24 dão-se como nascidos na região platina, 5 nasceram em Espanha, e is são originários de Portugal e do Brasil..20

A presença e a actividade destes ourives é referida na documentação da época. Em carta do governador da Colónia do Sacramento, António Pedro de Vasconcelos, ao rei, em 23 de M arço de 1726 , diz-se: Na ocazião em que se perdeo a nau caravella neste ryo, hindo dar a outra banda os passagei ros naufragados, se deixou ficar em Buenos Ayres hum ourives por nome J oseph dos Sanctos, que vinha para esta Praça, este se acha hoje ahy estabelecido com bom princi pio, e como a terra o hospedou bem deu ordem a que sua mulher passasse das I lhas ao Rio de Janeiro, e daquella cidade a esta Praça, a qual chegou há poucos dias com dous filhos, e querendo continuar a viagem para Buenos Ayres, em duvida se cabia na minha alçada, e como me paresse que não, e estou atacado de empenhos para este fim, principalmente de outro ourives de bom prepozito que aly há por nome Aleixo Alvarez em quem os Portuguezes que passão a outra banda achão um grande agazal ho, e conseguera por seu respeito os mayores negocios, entro a pedir a Vossa excelencia com todo o encarecimento queira dar a licença que se me pede, e mandarma expedir pella via do Rio de Janeiro no cazo que não saya dahy embarcação para este porto em tempo breve ${ }^{21}$

No domínio da ourivesaria, se a influência portuguesa se exerceu essencialmente através dos artistas lusos que passaram para Buenos Aires, há que

19. Cf. D amián Bayón, "Las artes aplicadas barrocas en Latinoamérica”, em Simposio Internazionale sul Barocco Latino Americano-Atti, vol. I Roma, Istituto I talo Latino Americano, I982, p. I59.

20. Véanse Adolfo Luís Ribera e H ector $\mathrm{H}$. Schenone, Platería sudamericana de los siglos XVII-XX, Buenos Aires, Banco de Itália y Rio de la Plata, I98I, p. 58.

2I. Arquivo H istórico U Itramarino, Lisboa-N ova Colónia do Sacramento-Caixa 2-D oc. 39, fl. 2 verso. 
recordar que quando o Vice-Rei C eballos ocupou a Colónia, em I777, o produto do saque de todas as suas igrejas foi distribuído pelos templos da capital do Rio da Prata; uma parte destes objectos de culto, produzidos por portugueses e de elevado valor artístico, manteve-se até aos nossos dias em Buenos Aires e constituiu certamente uma fonte de inspiração para os prateiros locais. $O$ livro de inventários do M osteiro de Santa Catarina de Sena de Buenos Aires tem registados os seguintes objectos provenientes dos templos da Colónia do Sacramento: Primeramente una cruz grande de plata con hasta de procesiones/ I tem. 0 tra de lo mismo para guión. / I tem. D os cande labros de lo proprio./ Item. U na custodia, de ítem que puede servir de cálix./ Item. Un cálix de ítem con su patena y cucharita./ [... ] Item. U na lâmpara de ítem./ [... ]Item. Cuatro palias./[... ]Item. Seis purificadores./[... ] Item. Un juego de sacras. ${ }^{22}$

Datam do século XVIII, no qual a influência portuguesa foi muito marcante, várias peças de ourivesaria, maioritariamente destinadas ao culto religioso, como píxides, ciriais, lâmpadas, tocheiros, cálices, turíbulos, custódias, sacras, navetas, coroas, etc. Algumas, raras, apresentam marcas de ourives brasileiros, activos no Rio de Janeiro.

As estantes litúrgicas são um dos objectos que espelham de forma mais original esta influência, no final do século XVIII. Conservam-se em Buenos Aires al guns exemplos com as formas e ornamentação do mobiliário de estilo D. José, muito apreciado na região. Em I773, o viajante Concolorcorvo, ao descrever Buenos Aires, não deixa de fazer referência ao gosto pelo mobiliário luso-brasileiro em madeira de jacarandá: $H$ ay pocas casas altas, pero unas y otras bastante desahogadas y muchas bien edificadas, con buenos muebles, que hacen traer de la rica madera del Janeiro, por la Colonia de Sacramento. ${ }^{23}$ Trata-se de peças com elevado peso de prata, fundidas, repuxadas e cinzeladas, apresentando decoração rocaille, remates assimétricos e pés elegantes, com dupla curvatura, que repetem a forma característica dos "pés de cabra" do mobiliário da época.

22. Libro de inventarios antiguos del M onasterio de Santa Catalina de Sena de Buenos Aires (cit. por Andrés M illé, El M onasterio de Santa Catalina de Sena de Buenos Aires-Evocación del siglo XVIII, tomo II, Buenos Aires, Pellegrini, 1955, pp. 317-318).

23. Concolorcorvo, El lazarillo de los ciegos caminantes desde Buenos Aires hasta Lima, Buenos Aires, Junta de H istoria y N umismática, 1908 (cit. por Ramón M ellero García, M anual informativo de la ciudad de Buenos Aires, Buenos Aires, Instituto $\mathrm{H}$ istórico de la Ciudad de Buenos Aires, I98I, p. 79). 
Todas estas peças são obras importantes para o contexto local, com grande peso de prata, e parecem corresponder a encomendas significativas por parte da hierarquia da I greja, ou a doações laicas de vulto. No seu conjunto, apresentam um grande primor de execução e uma boa qualidade técnica, que correspondem a padrões europeus, e provam que muitos artífices nascidos e educados em Portugal ou no Brasil transmitiram aos seus aprendizes as formas e os processos de trabalho aí assimilados. São peças de contornos muito marcados, com formas refinadas e uma ornamentação exuberante, fazendo corpo com o objecto, onde abundam as volutas, os concheados as cabeças de querubim, e toda uma iconografia erudita. A influência da gramática decorativa luso-brasileira barroca e rococó demarca estes objectos da restante produção local, e sobretudo da que era enviada do Alto Perú.

Através de uma análise formal comparativa de obras de prataria conservadas em colecções e museus brasileiros, nomeadamente no M useu Arquidiocesano de $M$ ariana, no $M$ useu $M$ ineiro de Belo $H$ orizonte, no $M$ useu do O uro de Sabará e na colecção de M árcia M oura Castro, de Belo H orizonte ( $M$ inas $G$ erais), bem como de peças da colecção da Arquidiocese de $O$ linda e Recife, do M osteiro de São Bento de Olinda, e de J. Maciel N eto, Recife (Pernambuco), e do M useu Carlos Costa Pinto, do Salvador (Bahia), com as suas congéneres rioplatenses, procuraremos demonstrar visualmente como, no campo das artes decorativas, se verificou uma clara aceitação dos padrões estéticos portugueses, pela via luso-brasileira, em detrimento da influência peruana ou al toperuana.

A corrente de gosto criada acompanha, aliás, o próprio fluxo migratório, muitas vezes clandestino, dos portos brasileiros para Buenos Aires, e põe em causa o clássico modelo teórico centro-periferia, que assenta mais em considerações político-económicas do que na análise dos fenómenos da arte e da cultura. Assim, poderíamos afirmar que, se pensássemos num mapa das províncias artísticas para o século XvIII na América do Sul, e atendendo estritamente ao campo das artes decorativas, a zona correspondente ao Rio da Prata mais facilmente integraria a região do Brasil do que o Sul e Leste da América do Sul, se seguirmos a divisão proposta por G eorge Kubler. † 